\title{
Pericapsular soft tissue as a pain generator in hip osteoarthritis: considerations for developing a new home exercise to prevent surgery
}

\author{
Kazuo Hayashi ${ }^{1 *}$ and Toshiharu Tsunoda ${ }^{2}$ \\ ${ }^{1}$ Arthritis Center, Fukuoka Wajiro Hospital, Japan \\ ${ }^{2}$ Department of Orthopedic Surgery, Asama General Hospital, Japan
}

In previous studies by Fernandes et al. [1] and Svege et al. [2], the inclusion criteria of exercise as a non-surgical treatment for osteoarthritis (OA) of the hip included a Harris Hip Score (HHS) between 60 and 95 points, and total hip arthroplasty (THA) was indicated for patients with an HHS below 60 points. A number of studies have examined participants with mild to moderate $\mathrm{OA}$ of the hip [1-5] In a randomized clinical trial, Bennell et al. [6] implemented a multimodal physical program for patients with OA of the hip [6]. Their results revealed that the physical therapy program conferred no additional clinical benefit over a realistic sham condition for $51 \%$ of patients with moderate to severe OA of the hip, and it was reported that the program was associated with relatively frequent but mild adverse effects [6,7]. Most studies of exercise interventions for OA have examined muscle strength training, stretching, functional training, and aerobic fitness programs [8]. However, functioning of patients with moderate to severe OA of the hip has not been reported to improve using these exercise methods alone.

However, many patients with an HHS below 60 points wish to postpone surgery for a range of reasons, including work, child-rearing, or caring for parents, when seen on an outpatient basis. We have found that many patients with OA of the hip complained of hip pain at standing and at first step when starting to walk but decreased hip pain during walking. Many patients experience motion pain with no walking pain or mild walking pain. This phenomenon has been observed even in patients with an HHS below 60 points. We speculate that motion pain can be caused by contracture of the hip joint, whereas walking pain can be caused by contact of the subchondral bone after the cartilage has disappeared from the joint surface. This suggests that motion pain could be decreased by exercise, whereas walking pain may be decreased by surgery. An anterior pelvic tilt and elevation of the greater trochanter of patients with OA of the hip can cause apparent shortening of leg length on the affected side. This apparent difference in leg length can result in instability while walking. We considered that this instability may cause repetitive pericapsular soft tissue (joint capsule, ligaments, inner muscles) injury, resulting in contracture of the affected hip. Thus, correction of pelvic malalignment before a strengthening exercise is necessary in addition to decontracture exercise of the affected hip to decrease motion pain. Decontracture may provide a useful method to ease joint stiffness.

We developed a decontracture and pelvic realignment exercise technique called the pericapsular soft tissue and realignment of the pelvis (PSTR) exercise [9]. In a retrospective study, PSTR exercise induced significant improvement in patients with OA of the hip (Table 1 and Figure 1) [9]. In addition, PSTR exercise resulted in a significant improvement even in patients with an HHS below 60 points (Figures 2 and 3) [10]. We have begun a multicenter prospective single-arm study to confirm the effects of PSTR exercise [11]. We plan to investigate the decontracture test to differentiate between motion pain and walking pain to determine surgical indications in future studies.

\section{Acknowledgments}

PSTR exercise is a part of the Yuki program developed by Teruo Ooyati (Osaka, Japan). We thank Benjamin Knight, MSc., from Edanz Group (www.edanzediting.com/ac) for editing a draft of this manuscript.

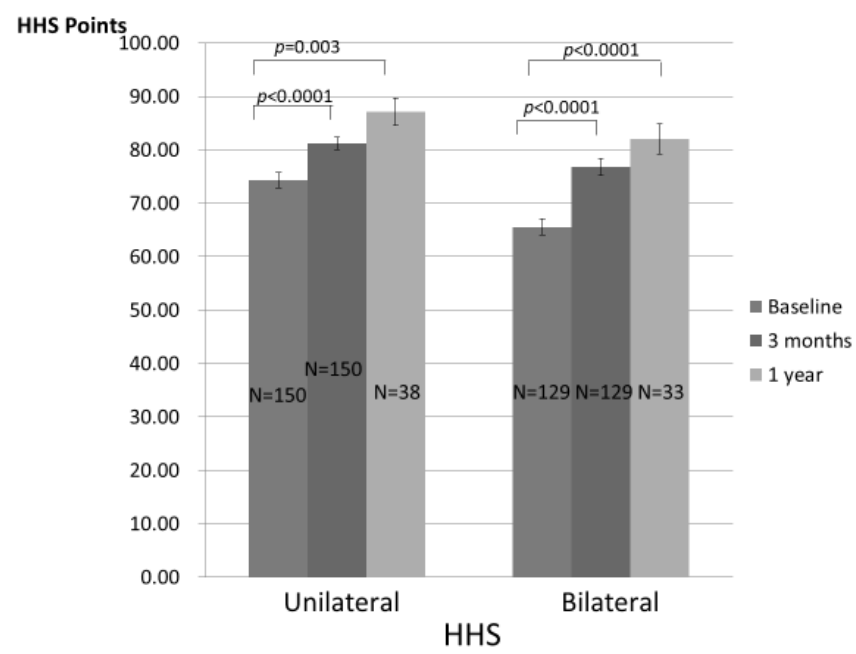

Figure 1. HHS change after PSTR exercise in patients with an HHS above 60 and below 59 points at baseline

Unilateral: Group with unilateral OA of the hip (no pain in the opposite hip) Bilateral: Group with bilateral OA of the hip (pain in the opposite hip)

${ }^{\star}$ Correspondence to: K Hayashi, Arthritis Center, Fukuoka Wajiro Hospital, Fukuoka, Japan, E-mail: hayashis@giga.ocn.ne.jp

Received: June 06, 2018; Accepted: June 22, 2018; Published: June 28, 2018 


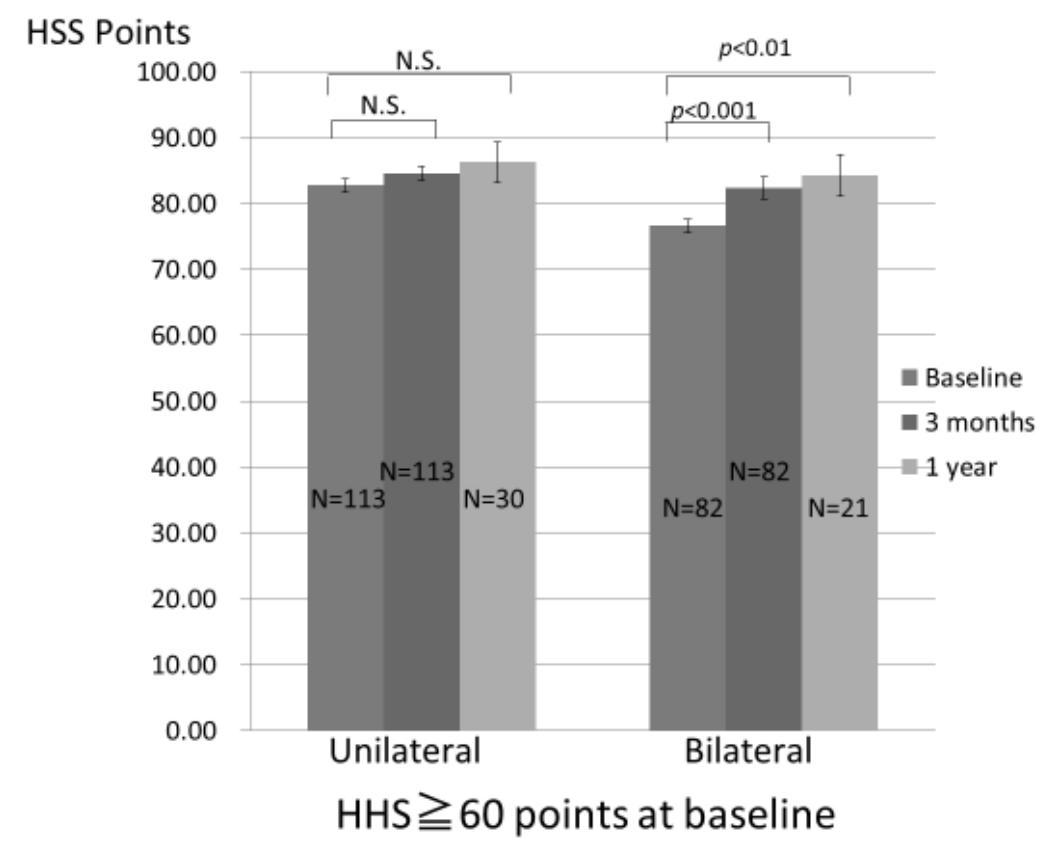

Unilateral: Group with unilateral OA of the hip (no pain in the opposite hip)

Bilateral: Group with bilateral OA of the hip (pain in the opposite hip)

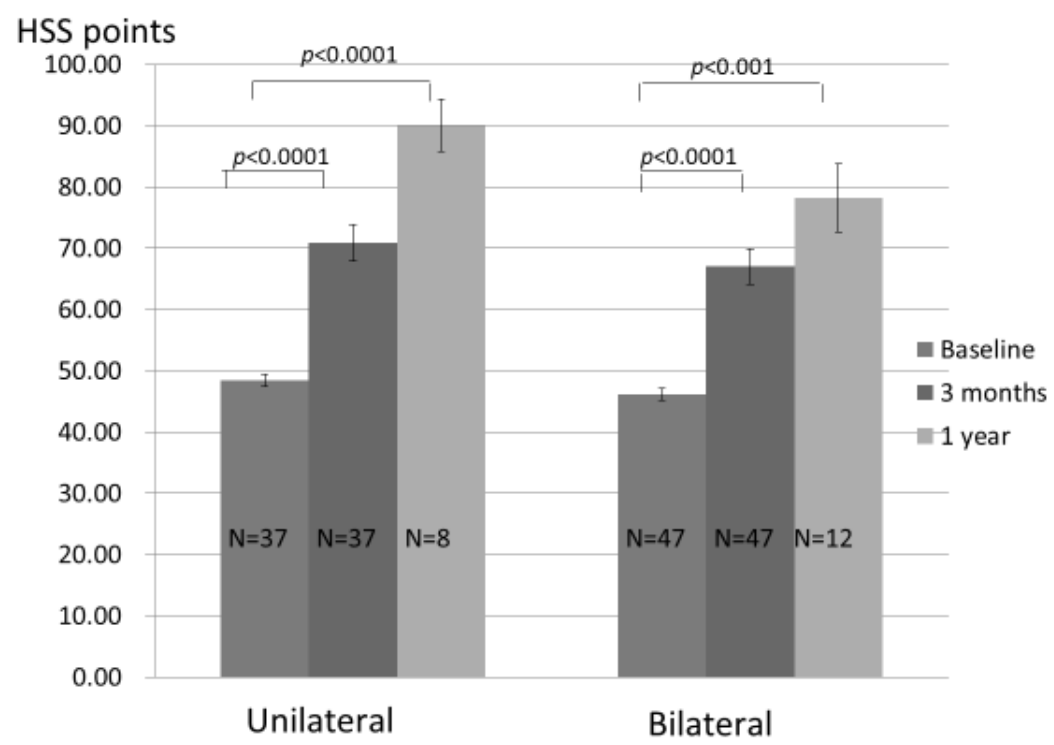

$\mathrm{HHS}<60$ points at baseline

Figure 3. HHS change after PSTR exercise in patients with an HHS below 59 points at baseline

Unilateral: Group with unilateral OA of the hip (no pain in the opposite hip)

Bilateral: Group with bilateral OA of the hip (pain in the opposite hip)

Table 1. Baseline characteristics

\begin{tabular}{|c|c|c|}
\hline Mean \pm S.D. & Unilateral Group(n=154) & Bilateral Group(n=131) \\
\hline Age (years) & $56.4 \pm 14.2$ & $54.2 \pm 12.8$ \\
\hline Women, no.(\%) & $133(86.4 \%)$ & $123(93.9 \%)$ \\
\hline BMI $\left(\mathrm{kg} / \mathrm{m}^{2}\right)$ & $22.0 \pm 3.3$ & $22.1 \pm 3.2$ \\
\hline HHS $(0-100)$ & $74.14 \pm 17.79$ & $65.35 \pm 17.24$ \\
\hline No. (\%) below 59 & $\mathrm{n}=38(25.0 \%)$ & $\mathrm{n}=49(37.4 \%)$ \\
\hline No. $(\%)$ above 60 & $\mathrm{n}=114(75.0 \%)$ & $\mathrm{n}=82(62.6 \%)$ \\
\hline Duration of pain (months) & $30.8 \pm 50.4$ & $55.7 \pm 98.7$ \\
\end{tabular}




\section{Reference}

1. Fernandes L, Storheim K, Sandvik L, Nordsletten, L, Risberg (2010) Efficacy of patient education and supervised exercise VS patient education alone in patients with hip osteoarthritis: A single blind randomized clinical trial. Osteoarthritis Cartilage 18: 1237-1243. [Crossref]

2. Svege I, Nordsletten L, Fernandes L, Risberg MA (2015) Exercise therapy may postpone total hip replacement surgery in patients with hip osteoarthritis: a long-term follow-up of a randomised trial. Ann Rheum Dis 74: 164-169. [Crossref]

3. Maly MR, Robbins SM (2014) Osteoarthritis year in review 2014: rehabilitation and outcomes. Osteoarthritis Cartilage 22: 1958-1988. [Crossref]

4. Eizen, I, Fernandes L, Norsletten L, Risberg MA (2015) No effects of a 12-week supervised exercise therapy program on gait in patients with mild to moderate osteoarthritis: A secondary analysis of a randomized trial. J Negat Results Biomed 14 1-11 [Crossref]

5. Kemp JL, Moore K, Fransen M, Russell TG, Crossley KM (2015) A phase II tria for the efficacy of physiotherapy intervention for early-onset hip osteoarthritis: Study protocol for a randomized controlled trial. Trials 16: 1-8 [Crossref]
6. Bennell KL, Egerton T, Martin J, Abbott JH, Metcalf B, et al. (2014) Effect of physical therapy on pain and function in patients with hip osteoarthritis: a randomized clinical trial. JAMA 311: 1987-1997. [Crossref]

7. White DM1, Cibulka MT2, Woehrle J3 (2014) Physical therapy and hip osteoarthritis. JAMA 312: 1257. [Crossref]

8. Fransen M, McConnell S, Hernandez-Molina G, Reichenbach S (2009) Exercise for osteoarthritis of the hip. Cochrane Database Syst Rev CD007912. [Crossref]

9. Hayashi K, Ooyati T (2015) Dramatic effects of a new home exercise to improve hip function for patients with osteoarthritis. Osteoarthritis Cartilage 23, Supplement 2: A165-A166.

10. Hayashi K, Ooyati, T, Haruguti, K, Tobo Y (2017) Clinical trials of PSTR exercise (Yuki program) for hip osteoarthritis in patients with a Harris Hip Score below 60 points. Hip Joint 43: 1001-5 (in Japanese).

11. Hayashi K (2017) Investigation regarding effects of PSTR (pericapsular soft tissue and realignment) exercises to improve function in patients with osteoarthritis of the hip and a Harris Hip Score (HHS) below 60 points. (UMIN000028277).

Copyright: $(02018$ Hayashi K. This is an open-access article distributed under the terms of the Creative Commons Attribution License, which permits unrestricted use, distribution, and reproduction in any medium, provided the original author and source are credited. 